\title{
Visual Acuity, Quality of Vision, and Patient-Reported Outcomes After Bilateral Implantation with a Trifocal or Extended Depth of Focus Intraocular Lens
}

This article was published in the following Dove Press journal: Clinical Ophthalmology

\author{
Dan B Tran' \\ Ashley Owyang' \\ Jin Hwang' \\ Richard Potvin $\mathbb{D}^{2}$ \\ 'Coastal Vision Medical Group, Orange, \\ CA, USA; ${ }^{2}$ Science in Vision, Bend, \\ OR, USA
}

Purpose: To evaluate the visual acuity, quality of vision and patient reported outcomes for patients that were either bilaterally implanted with a trifocal intraocular lens (IOL) or an extended depth of focus (EDOF) IOL.

Design: Single site, prospective, non-interventional, masked, two-arm comparative study.

Methods: Subjects who had prior uncomplicated cataract surgery with bilateral implantation of one of the lenses above were evaluated. Subjects in each group were assessed during a single visit. The uncorrected and best distance-corrected binocular near $(40 \mathrm{~cm})$, intermediate $(60 \mathrm{~cm})$, and distance visual acuity (VA) were measured, along with a spectacle independence questionnaire, a quality of vision questionnaire and contrast sensitivity measured in both mesopic and photopic conditions.

Results: The study included 23 EDOF and 25 trifocal subjects. Binocular Uncorrected VAs were similar at distance and intermediate, but about 1.5 lines better at near with the trifocal $(p<0.001)$. Binocular best corrected distance - VA was significantly better with the EDOF lens $(0.5$ lines, $\mathrm{p}<$ 0.001 ), though the mean VA was better than $20 / 20$ in both groups. Distance-corrected intermediate and near VA were significantly better with the trifocal IOL (1 line and 1.5 lines respectively, $\mathrm{p}<$ $0.001)$. Significantly more trifocal subjects had $20 / 25$ or better VA at all three test distances $(64 \%$ vs $4 \%, \mathrm{p}<0.001)$. Patient reported spectacle independence was significantly higher in the trifocal group, driven primarily by differences in near vision. Mesopic and photopic binocular contrast sensitivity, satisfaction and subjective quality of vision scores were similar between groups.

Conclusion: The trifocal IOL provided significantly better near vision (1.5 lines) with slightly worse distance vision ( 0.5 lines), while providing similar contrast sensitivity and visual quality. It may be the preferred choice for patients desiring more spectacle independence.

Keywords: trifocal IOL, EDOF IOL, presbyopia correction, cataract surgery, extended depth of focus

\section{Plain Language Summary}

Patients presenting for cataract surgery may now have the option to choose a replacement lens that might reduce their dependence on glasses for a range of vision, from distance to near. Generally, there is an increased possibility for visual disturbances such as glare or haloes with such lenses. There are several different lens options, each with strengths and weaknesses. Extended depth of focus, or EDOF, lenses are designed to "stretch" the range of vision, but there are limits to the range that can be achieved. Trifocal lenses create three distinct focal points for distance, intermediate and near vision, but they may have the potential for more visual disturbances than EDOF lenses.

Our study compared to vision, subjective visual quality and reported spectacle independence in two groups, one of which had the EDOF lens implanted and the other with
Correspondence: Dan B Tran

Coastal Vision Medical Group, 293

S. Main St., Suite 100, Orange, CA, 92868

USA

Email dantran@coastal-vision.com 
a relatively new type of trifocal lens implanted. We found no differences in visual disturbances between the groups, but the trifocal group reported much better near vision and much lower dependence on glasses for near work. It appears the new trifocal design may be most appropriate for patients wishing to reduce their dependence on glasses for near work.

\section{Introduction}

Presbyopia correction at the time of cataract surgery is of interest to many patients, with numerous options for them to consider. Major considerations are the distances at which a patient desires spectacle independence (eg, distance only, distance and computer work, or a full range of vision) and their tolerance for potential visual disturbances such as glare and haloes. There are two distinctly different approaches to improving intermediate and near vision for patients.

The first approach involves trying to increase the depth of focus provided by the intraocular lens (IOL). This design was created because there was the potential to reduce the visual disturbances associated with providing multiple distinct foci. The TECNIS Symfony ${ }^{\circledR}$ IOL is a diffractive extended depth of focus (EDOF) lens that does not create distinct foci for various distances but uses the diffractive elements to increase the range of focus of the lens. There are limits to the ability to extend the range of focus without significant deterioration in visual quality, so the lens provides better distance and intermediate vision than near vision. ${ }^{1-3}$ Making one eye slightly myopic ( $\sim .5$ to $0.75 \mathrm{D})$ in an effort to increase binocular near vision does not appear to be a viable modality for the lens because while near vision may be improved an increase in visual disturbances has been reported. $^{4}$

The second approach is to design a lens with multiple focal points, typically achieved using diffractive optics. The Panoptix ${ }^{\circledR}$ Trifocal IOL (Alcon, Fort Worth, USA) is one such lens. It is based on an aspheric diffractive quadrifocal IOL design that is functionally a trifocal IOL. It redistributes light energy in a unique manner to provide focal points at distance, intermediate $(60 \mathrm{~cm})$ and near $(40 \mathrm{~cm}) .^{5}$ This is different from a traditional trifocal where the intermediate would be half the dioptric distance of the near focus, resulting in either a relatively long intermediate focus (ie, $40 \mathrm{~cm}$ for near and $80 \mathrm{~cm}$ for intermediate), or a relatively short near focus (ie, $67 \mathrm{~cm}$ for intermediate and $33 \mathrm{~cm}$ for near). Studies have shown good distance, intermediate and near vision with the lens, with contrast sensitivity within the standard range for normal patients and good subjective vision. ${ }^{6-9}$

The purpose of the current study was to compare refractive results, binocular VA (at distance, intermediate and near), contrast sensitivity, patient reported spectacle independence and quality of vision between the Panoptix (Trifocal) and Symfony (EDOF) IOLs.

\section{Methods}

This study was a single-site prospective, noninterventional, masked, two-arm comparative study of clinical outcomes after bilateral implantation of a trifocal or EDOF IOL. The study was approved by an institutional review board (Salus IRB, Austin, TX, USA). All enrolled subjects signed an appropriate informed consent. The study was conducted in compliance with the tenets of the Declaration of Helsinki, Good Clinical Practice (GCP) and International Harmonization (ICH) guidelines. There was no clinical intervention, so registration of the study with any clinical trial registry was not required. Data are not available for sharing.

Using a beta (power) of 0.9 and an alpha (p) of 0.05 , it was determined that the required sample size to detect a significant difference between the near VA provided by both lenses using a 1 -sided test would require 23 subjects in each group.

Subjects over 40 years of age who had prior uncomplicated cataract surgery with bilateral implantation of one of the lenses above (Trifocal, EDOF) were enrolled; lenses could be toric or non-toric. All IOLs were planned using the Zeiss IOL Master (Carl Zeiss Meditec, Jena, Germany) and finalized during surgery using the Wavetec ORA System ${ }^{\circledR}$, an intraoperative aberrometer (Alcon, Forth Worth, TX). All subjects had to have a binocular best-corrected acuity after surgery of $0.1 \log$ MAR (20/25) or better. Subjects with ocular pathology that might have affected postoperative visual acuity (outside of refractive error) were excluded. Second eye surgery had to have been completed between 3 months and 2 years (75-800 days) before the study visit. All refractive targets for both eyes in both groups had to be plano, though choosing the IOL that was on the myopic side of plano when planning the EDOF result was typical at the site.

Subjects in each group were assessed during a single visit. The uncorrected and best distance-corrected binocular near $(40 \mathrm{~cm})$, intermediate $(60 \mathrm{~cm})$, and distance visual acuity were measured, and the monocular manifest refractions recorded. Binocular distance-corrected photopic and mesopic contrast sensitivity were measured using the 
Optec ${ }^{\circledR} 6500$ Functional Vision Analyzer (Stereo Optical Company, Inc., Chicago, IL) in both photopic and mesopic conditions. A spectacle independence questionnaire (the Patient Reported Spectacle Independence Questionnaire, or PRSIQ $)^{10}$ and a subjective visual quality questionnaire (the Quality of Vision questionnaire, or $\mathrm{Q}$ of $\mathrm{V})^{11}$ were also administered. The primary measure of interest was the binocular distance-corrected near visual acuity.

Clinical data and questionnaire responses were collected on appropriate case report forms and tabulated in Microsoft Access. Statistical analyses were performed using Statistica 12 (TIBCO Software Inc., Palo Alto, CA, USA). Parametric variables were compared using analysis of variance (ANOVA) while non-parametric comparisons were made using the Chi-squared test; in both cases the level of statistical significance was $\mathrm{p} \leq 0.05$.

\section{Results}

A total of 23 EDOF subjects and 25 trifocal subjects were identified for inclusion. Table 1 shows the comparative demographic and monocular postoperative exam data for the two groups. As can be seen, the mean IOL sphere power implanted was not statistically significantly different between the two groups. The follow-up time was significantly longer for the EDOF lens, but all eyes were seen more than 79 days after surgery so the effect of this was expected to be minimal, particularly given the inclusion criterion of binocular VA better than $0.1 \log$ MAR (20/ 25). The mean spherical equivalent refraction was also statistically significantly different, but the difference was on the order of $0.25 \mathrm{D}$, reflecting the recognized bias for a slightly more myopic target for the EDOF lens in the surgical planning process. Monocular corrected distance visual acuity (CDVA) was about a half line better in the EDOF group.
Figure 1 shows the binocular uncorrected visual acuity by IOL type and test distance. There was no statistically significant difference in the VA at distance or intermediate, but the trifocal provided statistically significantly better acuity at near (0.06 $\log$ MAR with the trifocal vs 0.19 $\log$ MAR with the EDOF lens, almost 1.5 lines different, $\mathrm{p}<0.001)$. Figure 2 shows the best distance-corrected visual acuity by IOL type and test distance. The EDOF lens provided statistically significantly better VA at distance (about half a line, $\mathrm{p}<0.001$ ), while the trifocal IOL provided statistically significantly better VA at intermediate (about one line, $\mathrm{p}<0.001$ ) and near (about two lines, $\mathrm{p}<0.001)$.

In addition to the mean differences above, the binocular performance of the IOLs was also evaluated on a subject-specific basis; 16 trifocal subjects and 1 EDOF subject had binocular uncorrected visual acuity of 0.1 logMAR (20/25) or better at all three test distances; this difference was statistically significant $(\mathrm{p}<0.001)$. When corrected for distance vision, 17 trifocal subjects and 1 EDOF subject had a visual acuity of $0.1 \log$ MAR (20/25) or better at all three test distances. Again, the difference was statistically significant $(\mathrm{p}<0.001)$.

Figures 3 and 4 show the comparison of the photopic and mesopic contrast sensitivity scores by IOL group at different spatial frequencies; these were measured without glare. There was no statistically significant difference in either photopic or mesopic contrast sensitivity at any spatial frequency.

Table 2 contains the results for the PRSIQ question for whether spectacles were needed by the subjects at different distances by IOL group. Only one subject in each group reported needing spectacles for distance or intermediate vision, but statistically significantly more subjects reported needing spectacles for near work in the EDOF group $(48 \%$

Table I Demographics and Monocular Diagnostic (Postoperative) Refractive and VA Data

\begin{tabular}{|l|c|c|c|}
\hline & Trifocal & EDOF \\
\hline Subjects/eyes & $25 / 50$ & $23 / 46$ \\
Male/female & $13 / 12$ & $6 / 17$ & 0.07 \\
Age (years) & $67 \pm 8(49$ to 80$)$ & $7 I \pm 9(51$ to 83$)$ & 0.11 \\
IOL Power implanted (D) & $18.5 \pm 3.3(12$ to 24$)$ & $20.0 \pm 4.5(9.5$ to 25.5$)$ & 0.06 \\
Follow-up (days) & $124 \pm 43(79$ to 245$)$ & $-0.25 \pm 0.37(-1.25$ to 0.375$)$ & $<0.0 I^{*}$ \\
MRSE (D) & $-0.00 \pm 0.34(-0.75$ to 0.625$)$ & $0.49 \pm 36(0.00$ to 1.50$)$ & $<0.0 I^{*}$ \\
Refractive Cylinder (D) & $0.38 \pm 0.29(0.00$ to 1.00$)$ & $-0.03 \pm 0.08(-0.16$ to 0.24$)$ & 0.12 \\
Monocular CDVA (logMAR) & $0.02 \pm 0.07(-0.10$ to +0.20$)$ & $<0.0 I^{*}$ \\
\hline
\end{tabular}

Note: ${ }^{*} p$ value is statistically significant $(<0.05)$

Abbreviations: VA, visual acuity; EDOF, extended depth of focus; MRSE, mean refraction spherical equivalent; D, diopters; CDVA, corrected distance visual acuity; logMAR, log of the minimum angle of resolution. 
Vertical bars denote 0.95 confidence intervals

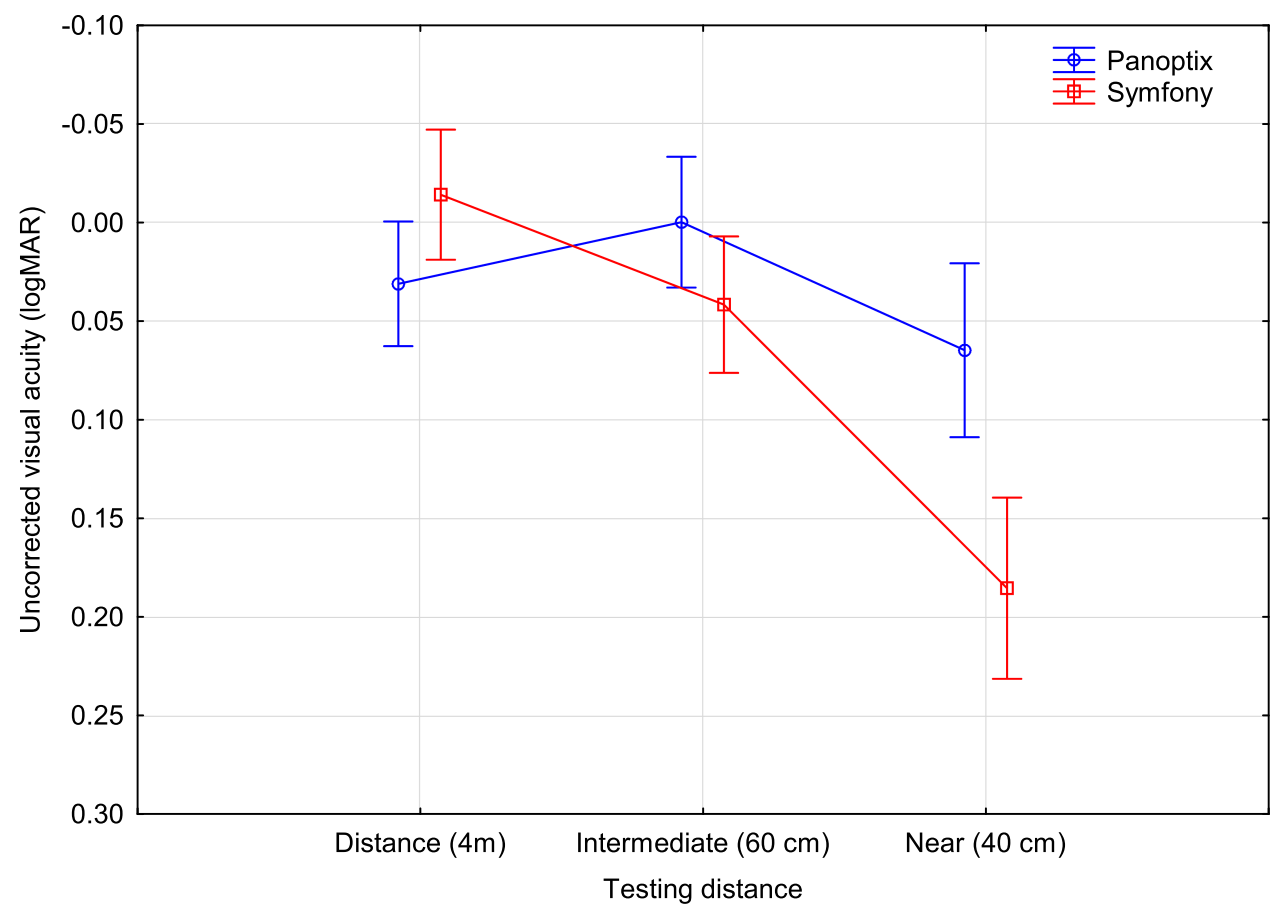

Figure I Binocular uncorrected visual acuity by distance and IOL type.

Abbreviations: $\log$ MAR, log of the minimum angle of resolution; EDOF, extended depth of focus.

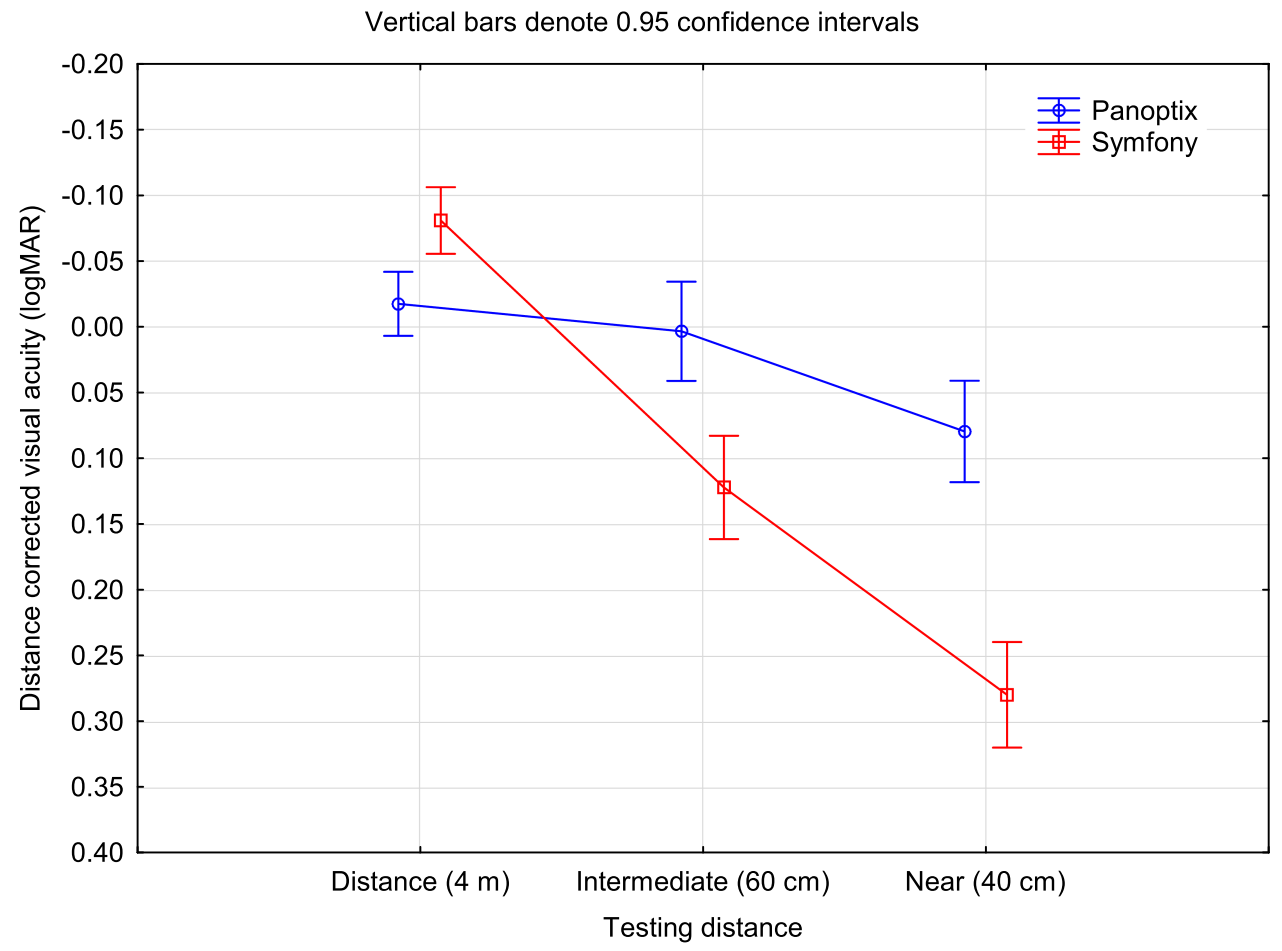

Figure 2 Binocular distance-corrected visual acuity by distance and IOL type.

Abbreviations: logMAR, log of the minimum angle of resolution; EDOF, extended depth of focus.

EDOF vs $12 \%$ trifocal, $\mathrm{p}=0.006)$. Table 3 contains a summary of the responses to the patient satisfaction question of the PRSIQ. There were no statistically significant differences in patient satisfaction reported between the two IOL groups at any of the test distances, nor for overall satisfaction. 


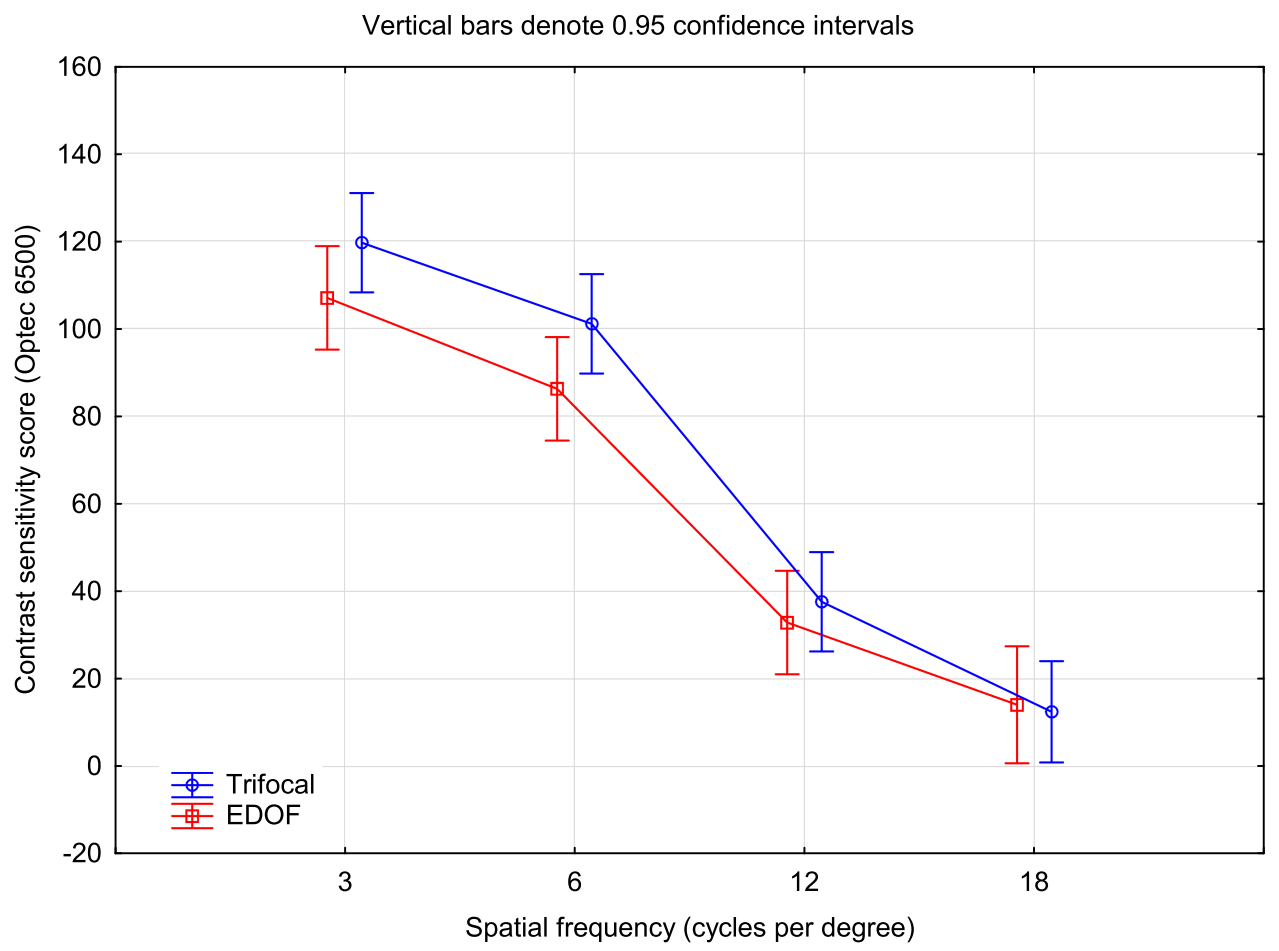

Figure 3 Photopic contrast sensitivity by IOL type.

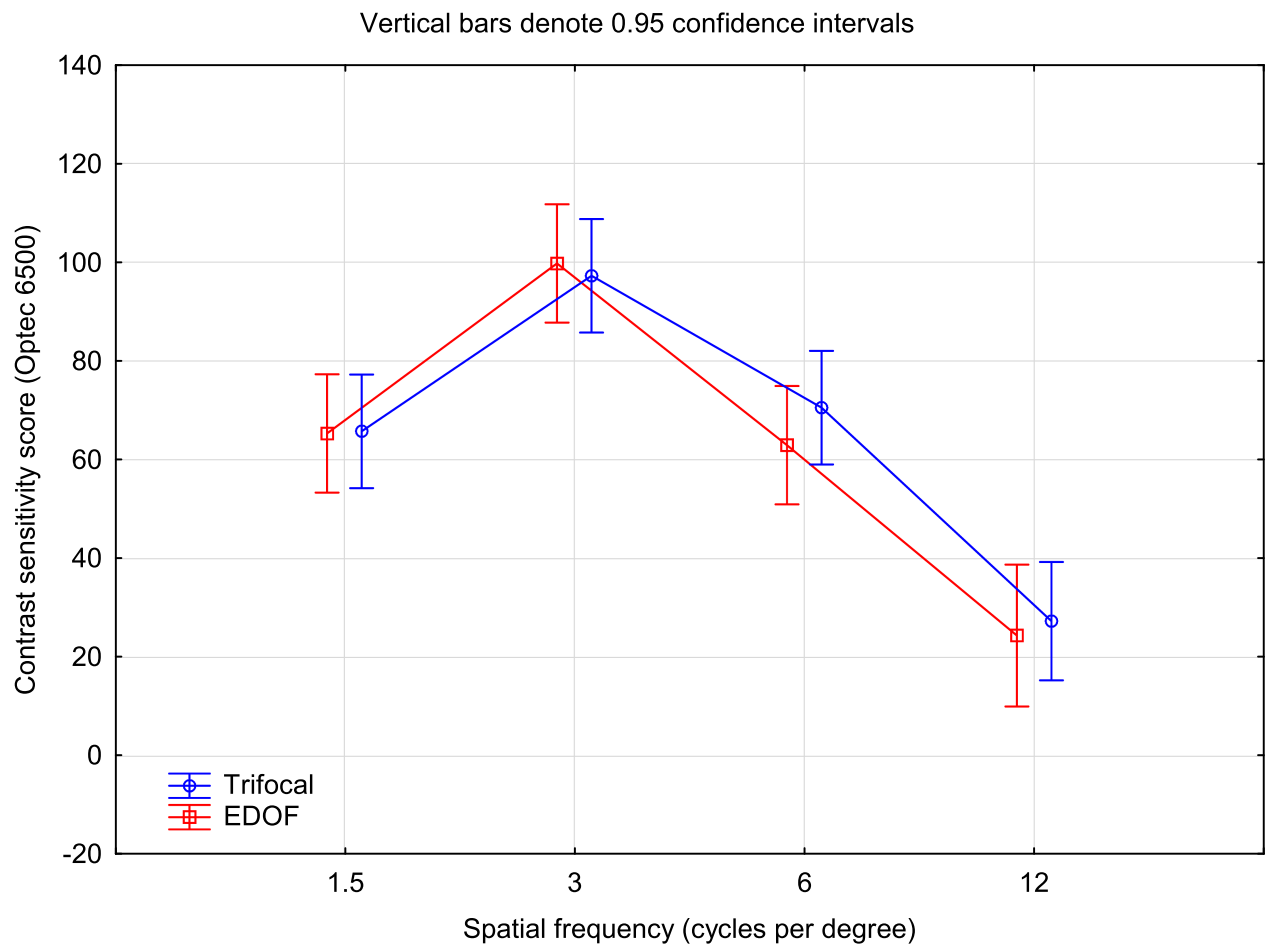

Figure 4 Mesopic contrast sensitivity by IOL type.

Table 4 summarizes the reported wearing time for spectacles after cataract surgery. While spectacle wear was reported to be similar for distance and intermediate vision between groups, significantly more subjects in the trifocal group reported never wearing spectacles for near vision $(84 \%$ vs $52 \%, \mathrm{p}=0.02)$ and overall $(96 \%$ vs $56 \%$, $\mathrm{p}=0.001$ ). Table 5 summarizes the reported ability to function without spectacles. Significantly more subjects 
Table 2 Reported Need for Spectacles by Distance and IOL Group

\begin{tabular}{|l|l|l|l|l|c|}
\hline Distance & Group & $\mathbf{n}$ & No & Yes & $\mathbf{p}$ \\
\hline Distance & EDOF & 23 & 22 & I & 0.95 \\
& Trifocal & 25 & 24 & I & \\
\hline Intermediate & EDOF & 23 & 22 & I & 0.95 \\
& Trifocal & 25 & 24 & I & \\
\hline Near & EDOF & 23 & 12 & II & 0.006 \\
& Trifocal & 25 & 22 & 3 & \\
\hline
\end{tabular}

Abbreviation: EDOF, extended depth of focus.

were able to function "all of the time" or "most of the time" without spectacles at near with the trifocal IOL ( $96 \%$ vs $74 \%, p=0.03$ ), and significantly more subjects with the trifocal IOL were able to function "all of the time" without spectacles overall ( $88 \%$ vs $57 \%, p=0.01)$.

The aggregated distribution of scores for the Rasch-scored Quality of Vision questionnaire are shown in Figure 5, summarizing the reported visual disturbances from the two IOL groups; these include such things as glare, haloes and starbursts. There was no statistically significant difference in the frequency of reported visual disturbances $(p=0.53)$, the severity of visual disturbances $(p=0.88)$ or the degree to which subjects found the visual disturbances bothersome $(p=0.67)$. In the Quality of Vision questionnaire, haloes and glare were the most commonly reported visual disturbances.

Table 6 shows the detailed ordinal scores for the frequency, severity, and degree of bother for Glare, Haloes and Starbursts. The Mann-Whitney $U$-test was used to determine if there were any statistically significant differences in these scores. As can be seen, the EDOF subjects had a statistically significantly higher frequency of starbursts, with greater severity reported, though the degree of bother was not statistically significantly different.

There were no adverse events reported in any subjects in either study group.

Table 3 Satisfaction with Vision by Distance and IOL Group

\begin{tabular}{|c|c|c|c|c|c|c|c|}
\hline \multirow[t]{2}{*}{ Distance } & \multirow[t]{2}{*}{ Group } & & \multicolumn{5}{|c|}{ Reported Satisfaction } \\
\hline & & & Completely & Mostly & Moderately & A Little & Not at All \\
\hline \multirow[t]{2}{*}{ Distance } & EDOF & 23 & 19 & 2 & 1 & & 1 \\
\hline & Trifocal & 25 & 17 & 7 & I & & \\
\hline \multirow[t]{2}{*}{ Intermediate } & EDOF & 23 & 18 & 4 & I & & \\
\hline & Trifocal & 25 & 18 & 7 & & & \\
\hline \multirow[t]{2}{*}{ Near } & EDOF & 23 & 10 & 11 & I & & 1 \\
\hline & Trifocal & 25 & 15 & 7 & I & 1 & 1 \\
\hline \multirow[t]{2}{*}{ Overall } & EDOF & 23 & 14 & 7 & I & 1 & \\
\hline & Trifocal & 25 & 17 & 8 & & & \\
\hline
\end{tabular}

Abbreviation: EDOF, extended depth of focus.

Table 4 Reported Frequency of Spectacle Wear by Distance and IOL Group

\begin{tabular}{|c|c|c|c|c|c|c|c|}
\hline & \multirow[t]{2}{*}{ Group } & \multirow[t]{2}{*}{$\mathbf{n}$} & \multicolumn{5}{|c|}{ Reported Frequency of Wear (Time) } \\
\hline & & & All & Most & Some & A Little & None \\
\hline Distance & $\begin{array}{l}\text { EDOF } \\
\text { Trifocal }\end{array}$ & $\begin{array}{l}23 \\
25\end{array}$ & & & 3 & I & $\begin{array}{l}19 \\
25\end{array}$ \\
\hline Intermediate & $\begin{array}{l}\text { EDOF } \\
\text { Trifocal }\end{array}$ & $\begin{array}{l}23 \\
25\end{array}$ & & & 1 & 3 & $\begin{array}{l}20 \\
24\end{array}$ \\
\hline Near & $\begin{array}{l}\text { EDOF } \\
\text { Trifocal }\end{array}$ & $\begin{array}{l}23 \\
25\end{array}$ & $\begin{array}{l}1 \\
1\end{array}$ & $\begin{array}{l}3 \\
1\end{array}$ & I & $\begin{array}{l}6 \\
2\end{array}$ & $\begin{array}{l}12 \\
21\end{array}$ \\
\hline Overall & $\begin{array}{l}\text { EDOF } \\
\text { Trifocal }\end{array}$ & $\begin{array}{l}23 \\
25\end{array}$ & I & 1 & $\begin{array}{l}3 \\
1\end{array}$ & 5 & $\begin{array}{l}13 \\
24\end{array}$ \\
\hline
\end{tabular}

Abbreviation: EDOF, extended depth of focus. 
Table 5 Reported Ability to Function without Spectacles by Distance and IOL Group

\begin{tabular}{|c|c|c|c|c|c|c|c|}
\hline & \multirow[t]{2}{*}{ Group } & \multirow[t]{2}{*}{$\mathbf{n}$} & \multicolumn{5}{|c|}{ Reported Ability to Function (Time) } \\
\hline & & & All & Most & Some & A Little & None \\
\hline Distance & $\begin{array}{l}\text { EDOF } \\
\text { Trifocal }\end{array}$ & $\begin{array}{l}23 \\
25\end{array}$ & $\begin{array}{l}19 \\
24\end{array}$ & $\begin{array}{l}2 \\
1\end{array}$ & & & 2 \\
\hline Intermediate & $\begin{array}{l}\text { EDOF } \\
\text { Trifocal }\end{array}$ & $\begin{array}{l}23 \\
25\end{array}$ & $\begin{array}{l}19 \\
24\end{array}$ & $\begin{array}{l}2 \\
1\end{array}$ & & & 2 \\
\hline Near & $\begin{array}{l}\text { EDOF } \\
\text { Trifocal }\end{array}$ & $\begin{array}{l}23 \\
25\end{array}$ & $\begin{array}{l}12 \\
19\end{array}$ & $\begin{array}{l}5 \\
5\end{array}$ & 3 & I & $\begin{array}{l}2 \\
1\end{array}$ \\
\hline Overall & $\begin{array}{l}\text { EDOF } \\
\text { Trifocal }\end{array}$ & $\begin{array}{l}23 \\
25\end{array}$ & $\begin{array}{l}13 \\
22\end{array}$ & $\begin{array}{l}7 \\
3\end{array}$ & I & 1 & I \\
\hline
\end{tabular}

Abbreviation: EDOF, extended depth of focus.

\section{Discussion}

The current study was designed to compare vision and visual quality, as well as subjective quality of vision and spectacle independence between a trifocal IOL and an EDOF IOL. An often-stated advantage of EDOF lenses is that visual disturbances will be lower relative to a trifocal IOL, which is the tradeoff for slightly worse near vision. We found better near vision with the trifocal IOL, though no difference in patient reported visual disturbances.

Visual acuities reported here appear consistent with previous findings, though the slightly lower CDVA in the trifocal group relative to the EDOF group appeared atypical. ${ }^{12-14}$ These studies universally agree that near vision with the trifocal IOL is better than with the EDOF lens, but they differ in the findings with regard to intermediate vision; one earlier study found no difference between the IOLs, ${ }^{12}$ one reported better intermediate with the EDOF lens ${ }^{13}$ and one reported better intermediate with the trifocal IOL. Differences, when reported, were on the order of one or two logMAR letters. With different VA measurement criteria, slight differences in test distance (eg, $66 \mathrm{~cm}$ vs $60 \mathrm{~cm}$ intermediate vision testing) and

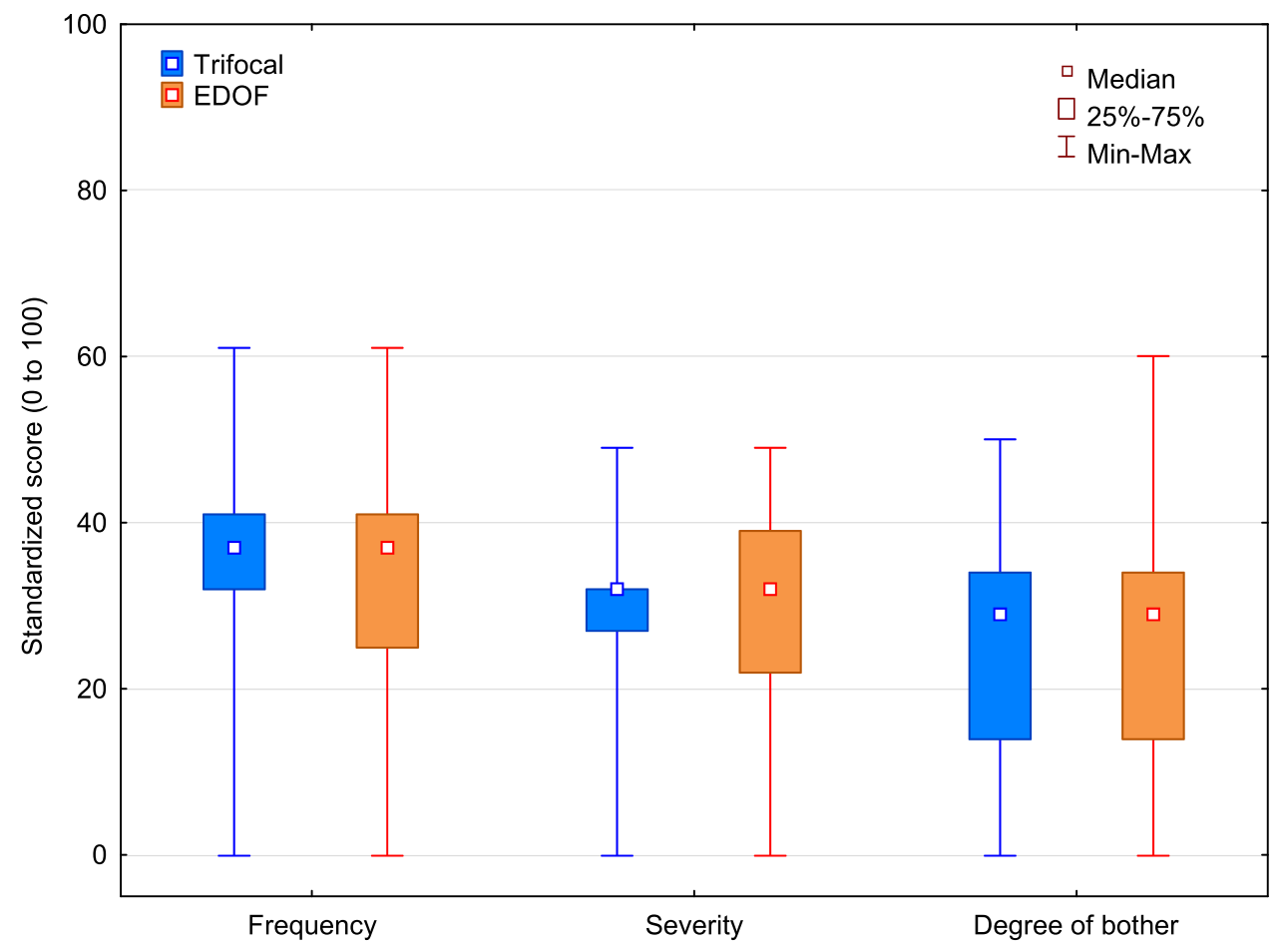

Figure 5 Summary scores for the Quality of Vision questionnaire. 
Table 6 Frequency, Severity and Degree of Bother for Select Visual Disturbances by IOL Group

\begin{tabular}{|c|c|c|c|c|c|c|c|}
\hline & Disturbance & IOL & Never & Occasionally & Quite Often & Very Often & $\mathbf{p}^{*}$ \\
\hline \multirow[t]{7}{*}{ Frequency } & Glare & EDOF & 12 & 7 & 2 & 2 & 0.43 \\
\hline & & Trifocal & 16 & 6 & 3 & & \\
\hline & Haloes & EDOF & 9 & 8 & 3 & 3 & 0.19 \\
\hline & & Trifocal & 7 & 4 & II & 3 & \\
\hline & Starbursts & EDOF & 8 & 10 & 3 & 2 & $0.03 *$ \\
\hline & & Trifocal & 18 & 5 & I & I & \\
\hline & Disturbance & IOL & Not at All & Mild & Moderate & Severe & $\mathbf{p}$ \\
\hline \multirow[t]{7}{*}{ Severity } & Glare & EDOF & 12 & 5 & 5 & I & 0.3 \\
\hline & & Trifocal & 16 & 7 & 2 & & \\
\hline & Haloes & EDOF & 9 & 6 & 6 & 2 & 0.69 \\
\hline & & Trifocal & 7 & 10 & 5 & 3 & \\
\hline & Starbursts & EDOF & 9 & 6 & 7 & I & $0.03 *$ \\
\hline & & Trifocal & 19 & 3 & 2 & I & \\
\hline & Disturbance & IOL & Not at All & A Little & Quite & Very & $\mathbf{p}$ \\
\hline \multirow[t]{6}{*}{ Degree of Bother } & Glare & EDOF & 12 & 6 & 3 & 2 & 0.25 \\
\hline & & Trifocal & 17 & 6 & 2 & & \\
\hline & Haloes & EDOF & 12 & 7 & 2 & 2 & 0.91 \\
\hline & & Trifocal & 12 & 9 & 3 & I & \\
\hline & Starbursts & EDOF & 13 & 7 & 2 & I & 0.13 \\
\hline & & Trifocal & 21 & 2 & 1 & 1 & \\
\hline
\end{tabular}

Notes: *Statistically significantly different, Mann-Whitney U-test, $\mathrm{p}<0.05$.

Abbreviation: EDOF, extended depth of focus.

lighting that was probably different, these slight variations are understandable.

With regard to contrast sensitivity, our finding of no difference between the lenses appears consistent with those of Ruiz-Mesa et $\mathrm{al}^{15}$ and Cochener et al. ${ }^{16}$ Mencucci et al reported significantly better contrast sensitivity with the EDOF lens, but there was no statistical testing indicated. ${ }^{17}$

Previous studies used different tests of patient functional vision and spectacle independence, so results are not directly comparable, but reported spectacle independence appeared higher for the trifocal IOL relative to the EDOF IOL in several studies, consistent with findings here. ${ }^{12-14,16}$ One other studies suggested spectacle independence was similar, but there were no details relate to how that spectacle independence was determined or evaluated. ${ }^{17}$ As noted earlier, the need for spectacles was primarily a function of the reduced near vision with the EDOF lens.

It is interesting to note that satisfaction results were high for both groups, including for near vision, in both this study and those previously reported. This is likely the result of setting appropriate patient expectations at the time of surgery, as satisfaction is generally tied to expectations. For instance, if subjects in the EDOF group were advised that near vision might be limited when they were choosing the lens, it is not an unexpected outcome after surgery; satisfaction with the outcome would therefore be unlikely to be affected.

Quality of vision scores were similar for subjects in the two IOL groups evaluated in the current manuscript. This suggests that any perceived benefit of using this EDOF lens to reduce the potential for visual disturbances may not actually be realized, which may be because it is based on a diffractive design, like the trifocal IOL. Starbursts were reported significantly more often and were reported to be more severe in the EDOF eyes. Quality of vision scores were higher (worse) than previous results that were recorded and reported in the same fashion for the trifocal lens in the current study. ${ }^{18}$ There may very well be a cultural component to responses; comparisons across different studies in different countries or regions may not be appropriate. Relative differences between lenses in the same study are unaffected by this observation. 
There are limitations to the current study. Because the practice switched from using the EDOF lens to the trifocal lens in this study, the follow-up times in both groups are different (though for reasons described above this was unlikely to have any major effect on refractive findings). Neuroadaptation, if it occurred, might have reduced the perception of visual disturbances and improved the subjective quality of vision in the EDOF group. Reported differences here may therefore be a bit conservative (eg, the significantly higher frequency and severity of starbursts in the EDOF group). The number of subjects in each group was also limited because the COVID-19 pandemic made recruitment difficult. Finally, sample sizes did not allow for any subanalysis based on whether the IOLs were toric or non-toric.

In conclusion, EDOF lenses are often suggested as an alternative to diffractive multifocal lenses when patients are concerned with the potential for visual disturbances, with the tradeoff being an expectation of worse near vision. Results in the current study suggest that this compromise is not necessary, as the visual disturbances and contrast sensitivity reported in the trifocal group were similar to those reported in the EDOF group. The improved near vision would argue for using the trifocal IOL in any patient interested in reducing their dependence on spectacles for near and intermediate work.

\section{Acknowledgments}

Interim results of this study were presented in a poster at the 38th conference of the European Society of Cataract and Refractive Surgeons (ESCRS), 2-4 October 2020 (virtual meeting). The poster's abstract was published in the online programme: https://www.escrs.org/amsterdam2020/pro gramme/posters-details.asp?id=36463. Brad Hall, PhD, of Sengi Data, aided in the preparation of this manuscript. This research was conducted with support from Alcon, in the form of an investigator-initiated study grant (IIT \#53268797).

\section{Disclosure}

Richard Potvin is a consultant to Alcon and Carl Zeiss Meditec. Dan B Tran is a consultant for and reports grants from Alcon. The authors report no other conflicts of interest in this work.

\section{References}

1. Cochener B, Concerto Study Group. Clinical outcomes of a new extended range of vision intraocular lens: international multicenter concerto study. J Cataract Refract Surg. 2016;42(9):1268-1275. doi:10.1016/j.jcrs.2016.06.033
2. Kohnen T, Böhm M, Hemkeppler E, et al. Visual performance of an extended depth of focus intraocular lens for treatment selection. Eye (Lond). 2019;33(10):1556-1563. doi:10.1038/s41433-019-0443-x

3. Attia MSA, Auffarth GU, Kretz FTA, et al. Clinical evaluation of an extended depth of focus intraocular lens with the salzburg reading desk. J Refract Surg. 2017;33(10):664-669. doi:10.3928/1081597X-20170621-08

4. Sandoval HP, Lane S, Slade SG, Donnenfeld ED, Potvin R, Solomon KD. Defocus curve and patient satisfaction with a new extended depth of focus toric intraocular lens targeted for binocular emmetropia or slight myopia in the non-dominant eye. Clin Ophthalmol. 2020;14:1791-1798. doi:10.2147/OPTH.S247333

5. Kohnen T. First implantation of a diffractive quadrafocal (trifocal) intraocular lens. J Cataract Refract Surg. 2015;41(10):2330-2332. doi:10.1016/j.jcrs.2015.11.012

6. Bissen-Miyajima H, Ota Y, Hayashi K, Igarashi C, Sasaki N. Results of a clinical evaluation of a trifocal intraocular lens in japan. Jpn J Ophthalmol. 2020;64(2):140-149. doi:10.1007/s10384-019-00712-4

7. Carreno E, Carreno EA, Carreno R, et al. Refractive and visual outcomes after bilateral implantation of a trifocal intraocular lens in a large population. Clin Ophthalmol. 2020;14:369-376. doi:10.2147/OPTH.S238841

8. Donmez O, Asena BS, Kaskaloglu M, Akova YA. Patients satisfaction and clinical outcomes of binocular implantation of a new trifocal intraocular lens. Int Ophthalmol. 2020;40(5):1069-1075. doi:10.1007/s10792-020-01390-9

9. Garcia-Perez JL, Gros-Otero J, Sanchez-Ramos C, Blazquez V, Contreras I. Short term visual outcomes of a new trifocal intraocular lens. BMC Ophthalmol. 2017;17(1):72. doi:10.1186/s12886-017-0462-y

10. Morlock R, Wirth RJ, Tally SR, Garufis C, Heichel CWD. PatientReported Spectacle Independence Questionnaire (PRSIQ): development and validation. Am J Ophthalmol. 2017;178:101-114. doi:10.1016/j.ajo.2017.03.018

11. McAlinden C, Pesudovs K, Moore JE. The development of an instrument to measure quality of vision: the Quality of Vision (QoV) questionnaire. Invest Ophthalmol Vis Sci. 2010;51(11):5537-5545. doi:10.1167/iovs.10-5341

12. Farvardin M, Johari M, Attarzade A, Rahat F, Farvardin R, Farvardin Z. Comparison between bilateral implantation of a trifocal intraocular lens (Alcon Acrysof $\mathrm{IQ}^{\circledR}$ PanOptix) and extended depth of focus lens (Tecnis ${ }^{\circledR}$ Symfony ${ }^{\circledR}$ ZXR00 lens). Int Ophthalmol. 2020. doi:10.1007/s10792-020-01608-w

13. Pedrotti E, Carones F, Talli P, et al. Comparative analysis of objective and subjective outcomes of two different intraocular lenses: trifocal and extended range of vision. BMJ Open Ophthalmol. 2020;5(1): e000497. doi:10.1136/bmjophth-2020-000497

14. Rementería-Capelo LA, García-Pérez JL, Gros-Otero J, Carrillo V, PérezLanzac J, Contreras I. Real-world evaluation of visual results and patient satisfaction for extended range of focus intraocular lenses compared to trifocal lenses. Int Ophthalmol. 2020. doi:10.1007/s10792-020-01563-6

15. Ruiz-Mesa R, Abengozar-Vela A, Ruiz-Santos M. A comparative study of the visual outcomes between a new trifocal and an extended depth of focus intraocular lens. Eur $J$ Ophthalmol. 2018;28 (2):182-187. doi:10.5301/ejo.5001029

16. Cochener B, Boutillier G, Lamard M, Auberger-Zagnoli C. A comparative evaluation of a new generation of diffractive trifocal and extended depth of focus intraocular lenses. J Refract Surg. 2018;34(8):507-514. doi:10.3928/1081597X-20180530-02

17. Mencucci R, Favuzza E, Caporossi O, Savastano A, Rizzo S. Comparative analysis of visual outcomes, reading skills, contrast sensitivity, and patient satisfaction with two models of trifocal diffractive intraocular lenses and an extended range of vision intraocular lens. Graefes Arch Clin Exp Ophthalmol. 2018;256(10):1913-1922. doi:10.1007/s00417-018-4052-3

18. Gundersen KG, Potvin R. Trifocal intraocular lenses: a comparison of the visual performance and quality of vision provided by two different lens designs. Clin Ophthalmol. 2017;11:1081-1087. doi:10.2147/ OPTH.S136164 


\section{Publish your work in this journal}

Clinical Ophthalmology is an international, peer-reviewed journal covering all subspecialties within ophthalmology. Key topics include: Optometry; Visual science; Pharmacology and drug therapy in eye diseases; Basic Sciences; Primary and Secondary eye care; Patient Safety and Quality of Care Improvements. This journal is indexed on PubMed

Submit your manuscript here: https://www.dovepress.com/clinical-ophthalmology-journal
Central and CAS, and is the official journal of The Society of Clinical Ophthalmology (SCO). The manuscript management system is completely online and includes a very quick and fair peer-review system, which is all easy to use. Visit http://www.dovepress.com/ testimonials.php to read real quotes from published authors. 